\title{
Emerging Late Adolescent Friendship Networks and Big Five Personality Traits: A Social Network Approach
}

\author{
Maarten Selfhout, ${ }^{1}$ William Burk, ${ }^{2}$ Susan Branje, ${ }^{3}$ \\ Jaap Denissen, ${ }^{4}$ Marcel van Aken, ${ }^{3}$ and Wim Meeus ${ }^{3}$ \\ ${ }^{1}$ Örebro University \\ ${ }^{2}$ Radboud University \\ ${ }^{3}$ Utrecht University \\ ${ }^{4}$ Humboldt-University Berlin
}

\begin{abstract}
The current study focuses on the emergence of friendship networks among just-acquainted individuals, investigating the effects of Big Five personality traits on friendship selection processes. Sociometric nominations and self-ratings on personality traits were gathered from 205 late adolescents (mean age $=19$ years) at 5 time points during the first year of university. SIENA, a novel multilevel statistical procedure for social network analysis, was used to examine effects of Big Five traits on friendship selection. Results indicated that friendship networks between just-acquainted individuals became increasingly more cohesive within the first 3 months and then stabilized. Whereas individuals high on Extraversion tended to select more friends than those low on this trait, individuals high on Agreeableness tended to be selected more as friends. In addition, individuals tended to select friends with similar levels of Agreeableness, Extraversion, and Openness.
\end{abstract}

Research has suggested that personality traits affect the development of existing social relationships (Asendorpf \& Denissen, 2006; Branje, Lieshout, \& Van Aken, 2004; Neyer, Banse, \& Asendorpf, 1999). In addition, similarity in specific personality traits has been shown to play an important role in friendship dyads (Hamm, 2000; Luo \& Klohnen, 2005; McPherson, Smith-Lovin, \& Cook, 2001; Selfhout,

Correspondence concerning this article should be addressed to Maarten Selfhout, Örebro University, Center for Developmental Research, Fakultetsgatan 1, SE-70182, Örebro, Sweden. E-mail: maartenvanzalk@gmail.com.

Journal of Personality 78:2, April 2010

(C) 2010, Copyright the Authors

Journal compilation (C) 2010, Wiley Periodicals, Inc.

DOI: $10.1111 / \mathrm{j} .1467-6494.2010 .00625 . x$ 
Branje, Raaijmakers, \& Meeus, 2007). Surprisingly, little is known about the main effects of personality traits compared to effects of similarity in these personality traits on friendship selection processes. Further, friendship dyads seem to be embedded within a larger social network of interconnected dyadic friendships and groups (Carrington, Scott, \& Wasserman, 2005; Wasserman \& Faust, 1994). Therefore, examining the role of personality in selection processes within friendship networks as a whole may be a more realistic approach than focusing exclusively on friendship dyads. In the current study, we utilize a social network approach to examine the development of emerging social networks and to investigate selection effects involving personality traits.

\section{Friendship Selection and Big Five Personality Traits}

Among the best developed models concerning personality traits is the Big Five personality model (Digman, 1990; McCrae \& Costa, 1994). This model consists of five personality factors, namely Openness (to experience), Conscientiousness, Extraversion, Agreeableness, and Neuroticism. The five factors have shown high rank-order and mean level stability over time (Roberts \& Mroczek, 2008) and exist in diverse cultures (McCrae \& Costa, 1994). The Big Five personality traits may affect friendship selection in at least three different ways. First, there may be personality differences in the number of friends individuals select (Asendorpf \& Wilpers, 1998). Second, personality may affect the extent to which individuals are being selected as a friend (Jensen-Campbell, Knack, Waldrip, \& Campbell, 2007). Finally, being similar in personality may affect friendship selection processes (Selfhout et al., 2007).

\section{Selecting Friends}

Extraversion is mainly related to one's social activity level and is thought to reflect the basic motivation to obtain rewards through social situations, making extraverted individuals more likely to experience positive affect in social situations (Denissen \& Penke, 2008a; Elphick, Halverson, \& Marszal-Wisniewska, 1998; Fleeson, Malanos, \& Achille, 2002; Freedman \& Doob, 1968). Because of this increased positive affect during social interactions, extraverted individuals may be more motivated to select friends. 
Empirical studies have examined effects of each of the Big Five traits on number of nominated friends and contact with nonacquainted individuals. One cross-sectional study showed that Extraversion, Conscientiousness, and Agreeableness were associated with more reciprocated friends for children (Jensen-Campbell et al., 2007). Nevertheless, these associations may be explained both by associations between personality and selecting friends and associations between personality and being selected as a friend (Sprecher \& Regan, 2002). Longitudinal studies show that only Extraversion predicted contacting more unacquainted fellow students over 7 weeks (Paulhus \& Trapnell, 1998) and more same-sex friends over 15 months (Asendorpf \& Wilpers, 1998) among undergraduates. Thus, these results suggest that only Extraversion longitudinally enhances friendship selection.

\section{Being Selected as a Friend}

Agreeable individuals tend to show more prosocial and altruistic behaviors, such as higher empathy (Nettle, 2006), higher willingness to cooperate (Denissen \& Penke, 2008a; Holmes, 2002), and more conflict strategies based on integration of both partners' views and needs ( Jensen-Campbell, Gleason, Adams, \& Malcolm, 2003). These prosocial behaviors may make Agreeable individuals more attractive as potential friends. Thus, Agreeableness may enhance being selected as a friend.

Cross-sectional studies provide inconsistent evidence for effects of personality traits on peer acceptance, which can be seen as a proxy for being selected more as a friend. For children, Extraversion, Conscientiousness, and Agreeableness were associated with more reciprocated friends (Jensen-Campbell et al., 2007). Among 12- to 18-year-old adolescents, higher Extraversion and Agreeableness were associated with more peer acceptance (Scholte, Van Aken, \& Van Lieshout, 1997). However, only Extraversion was associated with more peer acceptance among early adolescents, after adjusting for attractiveness, self-esteem, and class size (Lubbers, Van Der Werf, Kuyper, \& Offringa, 2006; Paulhus \& Trapnell, 1998). Thus, although evidence is inconsistent, Extraversion, Agreeableness, and Conscientiousness may be associated with higher peer acceptance. Notwithstanding, it is not clear whether these associations are due to selecting friends or being selected as a friend (Sprecher \& Regan, 2002). More insight can be gained into unique effects of personality 
traits on selecting friends versus effects on being selected as a friend by studying these effects simultaneously.

\section{Selecting Similar Friends}

The similarity-attraction hypothesis (e.g., Byrne, 1971) focuses on the role of similarity in personality traits in friendship selection, independent of main effects of personality traits. This perspective suggests that actual similarity in personality traits, or similarity between individuals' self-ratings and their friends' self-ratings of their own traits, increases attraction. Several mechanisms have been proposed to explain this effect. The reinforcement-affect explanation suggests that actual similarity reinforces individuals' opinions, views, and feelings and thereby triggers an implicit affective response that increases attraction (Clore \& Byrne, 1974). Uncertainty reduction theory indicates that actual similarity affords predictability, allowing individuals to communicate with less effort and greater confidence (Berger \& Calabrese, 1975). This increase in attraction will, in turn, enhance friendship selection. Thus, these theories predict that actual similarity in personality across all Big Five traits enhances friendship selection.

However, one recent study found weak cross-sectional and no associations over time between actual profile similarity across all Big Five traits and friendship intensity among just-acquainted freshmen (Selfhout, Denissen, Branje, \& Meeus, 2009). Nevertheless, it might be that similarity in two specific traits, namely Extraversion and Agreeableness, may enhance friendship selection. First, Extraversion seems to be directly linked to interaction styles used when getting acquainted with peers. Extraverted individuals seem to be more talkative and outgoing, whereas introverts seem to act more shyly and inhibitedly during initial interaction (Paulhus \& Trapnell, 1998). If two extraverted individuals meet, they may be able to predict each other's responses more easily and enjoy this interaction more than with a more inhibited, shy individual. Introverts, on the other hand, may enjoy the more inhibited interaction with each other more than with more outgoing, talkative extraverts and may be more able to predict each others' responses as well. Higher enjoyment and predictability have been specifically suggested to enhance attraction between individuals, leading to friendship formation (Berger \& Calabrese, 1975). Thus, similarity in Extraversion may increase similarity in interaction styles during acquaintanceship, which may 
enhance friendship selection through higher enjoyment and predictability between interaction partners.

In addition, recent studies suggest that Agreeableness is mainly expressed through altruistic behaviors (Denissen \& Penke, 2008a). Specifically, evolutionary game theory (Gilchrist, 2007; Maynard Smith, 1984) offers some hints that similarity in Agreeableness enhances friendship selection. Research on this theory suggests that individuals' altruism can only be considered as a successful collaboration strategy for the altruistic individual if the interaction partner acts altruistically as well. Specifically, if two individuals collaborate altruistically in so-called zero-sum games, the outcome is more beneficial for both individuals, because the shared efforts produce better results. However, if one of the two individuals acts egoistically, the person acting altruistically loses more than the one acting egoistically. If both individuals act egoistically, they gain less than when both act altruistically but at least more than when one of them acts egoistically. Therefore, similarity in altruistic behaviors can be expected to lead to more beneficial outcomes than dissimilarity in altruistic behaviors. In a similar vein, individuals who select others with similar levels of Agreeableness may benefit more from this relationship than when they select those who differ from them in Agreeableness. Hence, similarity in Agreeableness may enhance friendship selection.

Consistent with the notion that only similarity in Agreeableness and Extraversion plays an important role in friendships, Dutch same-sex adolescent friends tended to show actual similarity only in Extraversion and Agreeableness, regardless of sex differences in similarity (Selfhout et al., 2007). In contrast, studies did not find evidence for actual similarity in any of the Big Five traits among adolescent same-sex friends (Murphy, 2005) and in Conscientiousness among undergraduate friends (Lusk, MacDonald, \& Newman, 1998). Thus, these studies provide inconsistent evidence for actual similarity in Extraversion and Agreeableness in existing adolescent friendships.

\section{The Emergence of Friendship Networks in Late Adolescence}

The previously discussed studies examined friendships from a dyadic perspective, focusing on associations between personality and the relationship between two individuals. Late adolescents in Western 
industrialized countries, such as the Netherlands, typically go through a period of much change in occupational, educational, and social domains, such as moving out of the parental home, going to college, or starting to work. These transitions often make individuals move away from their old friendship networks and may create a high need to establish new friendship networks (Arnett, 2000; Asendorpf \& Wilpers, 1998).

Studies have described the development of adolescents' existing friendship networks in Sweden (Burk, Steglich, \& Snijders, 2007) and the Netherlands (Snijders \& Baerveldt, 2003). However, few studies examined the emergence of friendship networks in late adolescence. A study of 32 university freshmen showed that individuals who were getting acquainted tended to increasingly form reciprocated friendships (i.e., John selects Mark and Mark selects John) as well as transitive ties (i.e., John selects Sue, Sue selects Mark, and John selects Mark) over the course of the academic year (Van de Bunt, Van Duijn, \& Snijders, 1999). This suggests that late adolescents who are getting acquainted increasingly form cohesive friendship networks, over and above increasingly forming reciprocated relationships. Because of the small sample size, however, the generalizability of these findings may be limited. Therefore, more insight is needed about how friendship networks develop during acquaintanceship in late adolescence.

\section{The Current Study}

The current study contributes to knowledge about the development of emerging friendship networks and the role of Big Five traits herein in several unique ways. First, we examine the emergence of friendship networks in a naturalistic setting by focusing on incoming university freshmen in the Netherlands. For educational purposes, university freshmen at Utrecht University in the Netherlands were randomly placed in groups in which they worked together during the remainder of the year to complete a substantial part of the psychology curriculum, creating a naturalistic setting to study the formation of new friendships. Second, both main effects of personality traits (Neyer et al., 1999) and effects of similarity in personality (Sunnafrank \& Ramirez, 2004) on friendship selection have been suggested to work fast and directly in the acquaintanceship phase. To track these rapid changes, we examined university freshmen after they just got acquainted. Further, because individuals who select others as 
friends more frequently are more likely to be selected as a friend, effects of a personality trait on being selected as a friend may be confounded with effects of this personality trait on selecting friends.

To account for the complex dynamics of friendship selection, we used a social network approach to simultaneously examine personality effects on selecting friends, being selected as a friend, and selecting similar friends. In addition, using a social network approach allowed adjusting network effects on friendship selection. For example, the tendency of individuals to become friends with friends' friends means that transitivity affects friendship selection over time: Individuals seem to get to know others through the friends that they already have, using the social network structure to develop new friendships. To develop more realistic models of personality effects on friendship selection, one should therefore adjust for network effects such as transitivity. To achieve this, we used actor-based models of network dynamics (Snijders, 2001; Snijders, Steglich, \& Schweinberger, 2007) to examine the emergence of cohesive friendship networks as well as to simultaneously examine unique effects of personality on selecting friends, effects of personality on being selected as a friend, and effects of similarity in personality on selecting friends in late adolescence.

Regarding the development of late adolescent friendship networks over time, we expected that the network would become more cohesive over time. Specifically, we expected that the dyadic connections (e.g., the number of reciprocated friendships) as well as triadic connections (e.g., transitivity) would initially increase and then stabilize over time (Van de Bunt et al., 1999). We expected that Extraversion and Agreeableness would be associated with friendship selection during acquaintanceship. Because effects of personality traits on selecting friends and being selected as a friend may be confounded, we explored these effects simultaneously.

\section{METHOD}

\section{Participants}

Participants included 205 psychology freshmen $(M=18.9$ years, $S D=1.6)$ attending a university in Utrecht, which is a medium-sized city in the Netherlands. Participants filled out questionnaires at five monthly waves. The majority of participants were women $(n=168 ; 82 \%)$ 
and of Dutch origin $(n=189 ; 92 \%)$. About $52 \%(n=107)$ of the sample lived in Utrecht at the start of the study; after 4 months, $76 \%(n=156)$ lived in Utrecht. Additional analyses exploring differences between participants who lived in Utrecht and those who did not, both at the first and the last waves of the study, did not result in any significant $(p>.10)$ differences in Big Five traits or friendship intensity.

\section{Procedure}

During the second week of their first semester at the university, participants completed online questionnaires by accessing a website using a personal password. Participants filled out questionnaires that appeared in randomized order to avoid response sets. Confidentiality of all answers was explicitly guaranteed. The instruments used in the current study were part of a larger battery of assessments that took approximately 40 min to complete. For the follow-ups, participants were contacted through e-mail and mobile phones to remind them to complete the online questionnaire. An identical procedure was followed each of the next 4 consecutive months. Participants received $20 €$ (around \$25), 2 hours of course credit, and a personality feedback profile after successful completion of the study.

A total of 489 psychology freshmen students had been randomly assigned to 1 of the 20 introduction groups ranging between 16 and 24 individuals. E-mails, flyers, posters, and an announcement during the first university lecture generated attention for the current study. A total of 378 students $(77 \%$ of 489$)$ from 18 groups initially agreed to participate. Of these 378 students, we selected students from the 10 groups in which more than $80 \%$ of the group members filled out the online registration form. Of the 238 individuals in these groups, 221 agreed to participate (93\%). Participants and nonparticipants did not significantly differ in group size and age, $F(2,376)=.93, p>.10$. Further, these two groups did not significantly differ in gender, $\chi^{2}=2.68, d f=1, p>.05$. Participants in groups met up in mandatory university lessons throughout the year, ranging between 4 to $8 \mathrm{hr}$ a week. All measurements took place during weeks in which students attended university lessons, and these mandatory meetings did not significantly change in frequency throughout the study period. A measure of how much each participant communicated with his or her group members across the 4 months (ranging from $1=$ never to $7=$ very often $;=2.99, S D=1.83$ ) indicated that participants communicated regularly with one another within groups.

After 4 months, 205 individuals of the 221 participants at Wave 1 still took part in the current study ( $93 \%$ retention rate). Compared to these 205 participants, the 16 nonparticipating group members rated themselves as somewhat less neurotic (3.21 vs. $3.62, F=5.67, p<.05)$ and 
substantially less conscientious ( 3.92 vs. $4.75, F=22.74, p<.01)$. No differences were found for the other Big Five factors or number of friendship nominations.

\section{Measures}

\section{Personality Traits}

Each month, participants self-rated the revised Ten Item Personality Inventory (TIPI-r; Denissen \& Penke, 2008a; Gosling, Rentfrow, \& Swann, 2003). This instrument consists of five bipolar items (Extraversion: "extraverted, enthusiastic" vs. "reserved, quiet"; Agreeableness: "critical, quarrelsome" vs. "sympathetic, warm"; Conscientiousness: "dependable, self-disciplined" vs. "disorganized, careless"; Neuroticism: "anxious, easily upset" vs. "calm, emotionally stable"; Openness to Experience: "open to new experiences, complex" vs. "conventional, uncreative"). Participants rated themselves on these items, ranging from 1 (extremely like the left adjective pair) to 7 (extremely like the right adjective pair). A previous study examined reliability as well as validity of all five single items (Denissen, Geenen, Selfhout, \& Van Aken, 2008). Monthly test-retest reliability was medium to high for all single-item Big Five traits $(r>.55, p<.001)$. Further, the single items showed high $(r>.60, p<.001)$ interitem correlations with corresponding items of the same trait in the Big Five Inventory (Denissen, Geenen, Van Aken, Gosling, \& Potter, 2008).

\section{Friendship Nominations}

Each month participants described their relationship with each member of their group on a 6 -point scale $(1=$ far acquaintance, $2=$ acquaintance, $3=$ close acquaintance, $4=$ friend, $5=$ close friend, and $6=$ best friend $)$. An equivalent single-item scale has been shown to be predictive of proximity, amount of communication, attraction, and type of relationship over a period of 9 weeks (Sunnafrank \& Ramirez, 2004). We elected to dichotomize this scale to indicate presence or absence of friendship ties (i.e., $0=$ value less than 4 and $1=$ value greater than or equal to 4 ).

\section{Strategy of Analysis}

To analyze the effects of the Big Five on friendship network dynamics, we used actor-oriented models of network evolution (Snijders, 2001; Snijders, Steglich, Schweinberger, \& Huisman, 2006) implemented 
with the Simulation Investigation for Empirical Network Analyses (SIENA) software program (Snijders et al., 2006). This framework has been successfully applied to friendship networks in order to assess selection effects based on adolescent study program and smoking (Snijders, 2009) and delinquency in adolescence (Burk et al., 2007; Snijders \& Baerveldt, 2003). We first discuss assumptions of SIENA in a nontechnical way, followed by characteristics and parameters of the SIENA program relevant for the current study. The following descriptions are directly adopted from a nontechnical description by Snijders, Steglich, and Van de Bunt (in press). Technical explanations regarding SIENA are extensively explained elsewhere (Huisman \& Snijders, 2003; Snijders, 2009; Snijders et al., 2006, 2007).

For each of the 10 groups, the development of friendship networks across five waves is formally represented by five directed adjacency matrices consisting of dichotomous cells. Whereas outgoing ties from nonparticipating group members were coded as missing, ties from participants to nonparticipating group members were included in the data. In SIENA, friendships between individuals are binary variables, denoted by $x_{i j}$. A friendship tie $i \rightarrow j$ consists of a sender $i$, who is referred to as ego, and a receiver $j$, who is referred to as alter. A friendship tie between $i \rightarrow j$ is either existent or nonexistent at a given moment in time (values 1 and 0 , respectively). All these ties together make up the friendship network, represented by its $n \times n$ adjacency matrix $x=\left(x_{i j}\right)$ (self-ties are excluded). Changes in this friendship network as a whole are the dependent variables of our analysis. Put differently, effects of personality traits on selection processes are examined by studying these effects on changes of friendship ties in the peer network.

This way of modeling is based on several assumptions that are important to the current study (for a complete overview, see Snijders et al., in press). First, changes in this network are assumed to follow a continuous Markov chain across time (Katz \& Proctor, 1959; Wasserman \& Pattison, 1996). This means that although observations of friendship selection in themselves are discrete (i.e., individuals are either friends or not), the network change process itself is assumed to occur step by step (i.e., individuals do not become friends suddenly). To reflect this, the discrete changes are broken down into so-called microsteps, which represent smaller changes in the network as a whole. If we take an example of John forming a friendship with Sam, these two persons may not be connected at Time 1 and may mutually select each other as friend at Time 2 . Thus, discretely, this mutual friendship apparently exists at Time 2 "out of nothing." Nevertheless, it seems 
reasonable to assume that this friendship was formed step by step, as a consequence of reciprocation of this friendship tie or maybe even by other indirect connections that John and Sam had with each other through a third person, Sue. Prior studies regarding social networks among late adolescents have demonstrated that friendships seem to develop through reciprocation of friendship ties and the formation of triadic friendships (Knecht, 2008; Snijders et al., 2007; Van de Bunt et al., 1999). We addressed this assumption by examining these tendencies, to be discussed more fully under network effects. Second, future changes in the network are assumed to be the result of the current state of the network. This assumption implies that all relevant information concerning the current state of network is available in the data. Because we captured a friendship network from the initial phase in which adolescents start to know one another and the round-robin design ensures we have all the information concerning friendship ties between all individuals in the introduction groups, the current study is consistent with this assumption, and this assumption does not need to be additionally tested. A last assumption relevant for this study is that SIENA assumes that network ties are enduring states rather than brief events. That is, the program assumes friendship ties, after being formed, tend to endure over time. Because of the relatively short-term nature of this study, we were not able to fully test this assumption. Nevertheless, prior studies have indicated that adolescent friendship choices seem to endure (Brendgen, Vitaro, \& Bukowski, 2000; Bukowski \& Newcomb, 1984). Further, we did test for the stability of friendships in the current analysis to get an indication of the feasibility of this assumption.

To examine effects of the Big Five personality traits on friendship selection, two stages of estimation need to be distinguished. First, estimations were run for each of the 10 groups separately. Second, the estimates for each of the 10 groups were combined using a multilevel analysis (details follow below). Because of the multilevel structure of the current data (i.e., sociometric nominations were provided within each of the 10 introduction groups), group-level descriptives were weighted for group size before being aggregated. We first describe how the same estimation procedure was performed for the 10 groups separately.

Within each group, variables were entered in two steps. First, network effects were entered. We include four network effects: outdegree, reciprocity, transitivity, and geodesic distance-2. Outdegree describes the tendency of individuals to selectively nominate friends (i.e., individuals do not randomly nominate friends). Reciprocity describes the tendency for 
individuals to reciprocate a relationship (i.e., directed ties that are shared between dyadic partners). Transitivity and Geodesic distance-2 are two effects that each pertain to network closure, or the tendency of individuals to form triadic relationships over time. Geodesic distance-2 (GD-2) describes the tendency of individuals to form indirect ties (i.e., without forming a direct tie) to other individuals in the network. A technical way to describe such indirect connections is to say that the distance between individuals equals two network ties (hence the name of this parameter). When the GD-2 parameter is positive, individuals are unlikely to form direct ties with their friends' friends. By contrast, negative values of GD-2 suggest a tendency of individuals to nominate their friends' friends (statistically controlling for the number of indirect friendships, which is indexed by the transitivity parameter). For example, a negative GD-2 estimate would indicate that John is more likely to select Mark as a friend, given that John's friend Sue selected Mark as a friend (and regardless of any other indirect friendship to Mark). Transitivity describes the tendency for individuals to directly select the friends of their friends the more they are indirectly befriended with the former. For example, a positive transitivity effect would indicate that the more friends John has that are befriended with Mark, the more likely John will select Mark directly as a friend over time. Note that although these two network effects both pertain to the formation of triadic relationships, they differ in that transitivity is dependent on the number of indirect friendships, whereas GD-2 is independent of the number of indirect friendships. If reciprocity, transitivity, and GD-2 all significantly enhance friendship selection, this provides support for the earlier mentioned assumption of modeling with SIENA, namely, that friendship ties are formed in a step-by-step manner, through the structure of the friendship network.

We tested whether adding the effect of transitivity and the effect of GD-2 each significantly added to the fit. Score test statistics can be interpreted as approximate chi-square values, and therefore improvement of the fit values greater than 3.84 (with $\Delta d f=1, p<.05$ ) can be interpreted as model improvements (Schweinberger, 2005). This model comparison tests whether adding the two effects pertaining to cohesive peer networks (i.e., transitivity and GD-2) or individuals' tendency to become friends with their friends' friends significantly adds to model fit. Thus, including these effects allows us to examine whether it is warranted to use a social network approach such as SIENA over and above a dyadic approach. 
After including the four network effects, we include individual covariates when predicting changes in friendship ties: sex and the Big Five factors. For each of these six attributes, three parameters are estimated: the attribute ego parameter (effect of the attribute on selecting friends), the attribute alter parameter (effect of attribute on being selected as a friend), and the attribute similarity parameter (tendency for individual to select friends with similar levels of attribute). Taking Extraversion as an example, a positive Extraversion ego effect indicates that those high on Extraversion tend to have a higher number of outgoing friendship nominations than those low on Extraversion. A positive Extraversion alter effect indicates those high on Extraversion tend to have a higher number of incoming friendship nominations. A positive Extraversion similarity effect indicates individuals tend to nominate friends with similar levels of Extraversion. Parameters describing participant sex may be interpreted in a similar manner. Thus, a total of 18 parameters were simultaneously entered in the model: ego, alter, and similarity effects of sex and the five personality traits. Because of this exploratory nature of this study, we adopted a two-sided significance test with a significant level of at least $p<.01$. Significance is calculated by dividing estimates by their standard errors, adjusted for unreliable standard error across groups.

SIENA provided parameter values $\left(\beta_{k}\right)$ for the network effects and effects of individual covariates. We start with providing a technical explanation of an interpretation of $\beta_{k}$, followed by a conceptual interpretation. As discussed before, the dependent variable is changes in the network from friendship ties being absent (value of $0 ; x_{a}$ ) to being present (value of $1 ; x_{b}$ ) or vice versa. Interpretation of $\beta_{k}$ on these changes is as follows: When individual $i$ changes one of his or her friendship ties, then $f_{i}\left(x_{b}, \beta_{k}\right)-f_{i}\left(x_{a}\right.$, $\beta_{k}$ ) is the log odds ratio for individual $i$ to choose between friendships being present or absent, where $\beta$ refers to the specific individual covariate predicting friendship changes. This makes the probability of either of these friendship ties being present or absent $\exp \left(f_{i}\left(x_{b}, \beta_{k}\right)-f_{i}\left(x_{a}, \beta_{k}\right)\right)$. Nevertheless, in this case, the rate at which individuals change their friendship ties is assumed to be same for all individuals. As individual differences in the rates changes occur in friendship ties are of interest for our research questions (e.g., whether more Extraverted persons change their ties more than less extraverted persons), SIENA estimated the rate change for different levels of the individual covariate in question (see Snijders et al., 2010). Conceptually, higher significant values of $\beta_{k}$ in the current study indicate that individuals tend to form a friendship in the network over and above chance when scoring higher on the individual covariate, holding all other 
effects constant. The effects are assumed to be constant across the whole period of time.

After we estimated network effects and individual covariate effects for each of the 10 groups, we used the multilevel analysis to analyze the mean network and individual covariate effects across the 10 groups (for technical details, see Snijders \& Baerveldt, 2003). In this meta-analysis, the parameter estimates obtained for each introduction group separately were combined in a way that accounted for the fact that the differences between the parameter estimates are composed of real variability together with unreliable (error) variability. The latter was reflected by the standard errors of the parameter estimates. One assumption of this method, as in other multilevel methods (Cochran, 1954; Hedges \& Olkin, 1985), is that the estimated mean effect across all groups is independent of the standard errors of this estimated mean effect. This was checked by examining plots provided by the SIENA program that showed distributions of mean effects and their standard errors. These plots showed no indication of any association between the mean effects and their standard errors. Finally, it was tested whether the variance of each mean effect was significantly different from zero to examine whether introduction groups differ in how personality predicted friendship selection (homogeneity between groups).

\section{RESULTS}

\section{Descriptive Analyses}

Table 1 presents weighted means (according to group size) of the structural characteristics across the 10 friendship networks and individual personality measures over the five waves. These describe how the emerging friendship network develops over time. The indices describing the structural characteristics of the networks collectively indicate a tendency toward network expansion over 3 months, followed by subsequent stabilization. Specifically, the average degree, or average number of outgoing network ties, tends to increase over the first 3 months. After that, these numbers tend to remain relatively stable. The reciprocity and transitivity indices reflect the proportion of reciprocated friendship ties and proportion of transitive triplets, respectively. These indices indicated growth that gradually tends to stabilize over the course of the study. Taken together, these indices suggest an increase in connections within the 


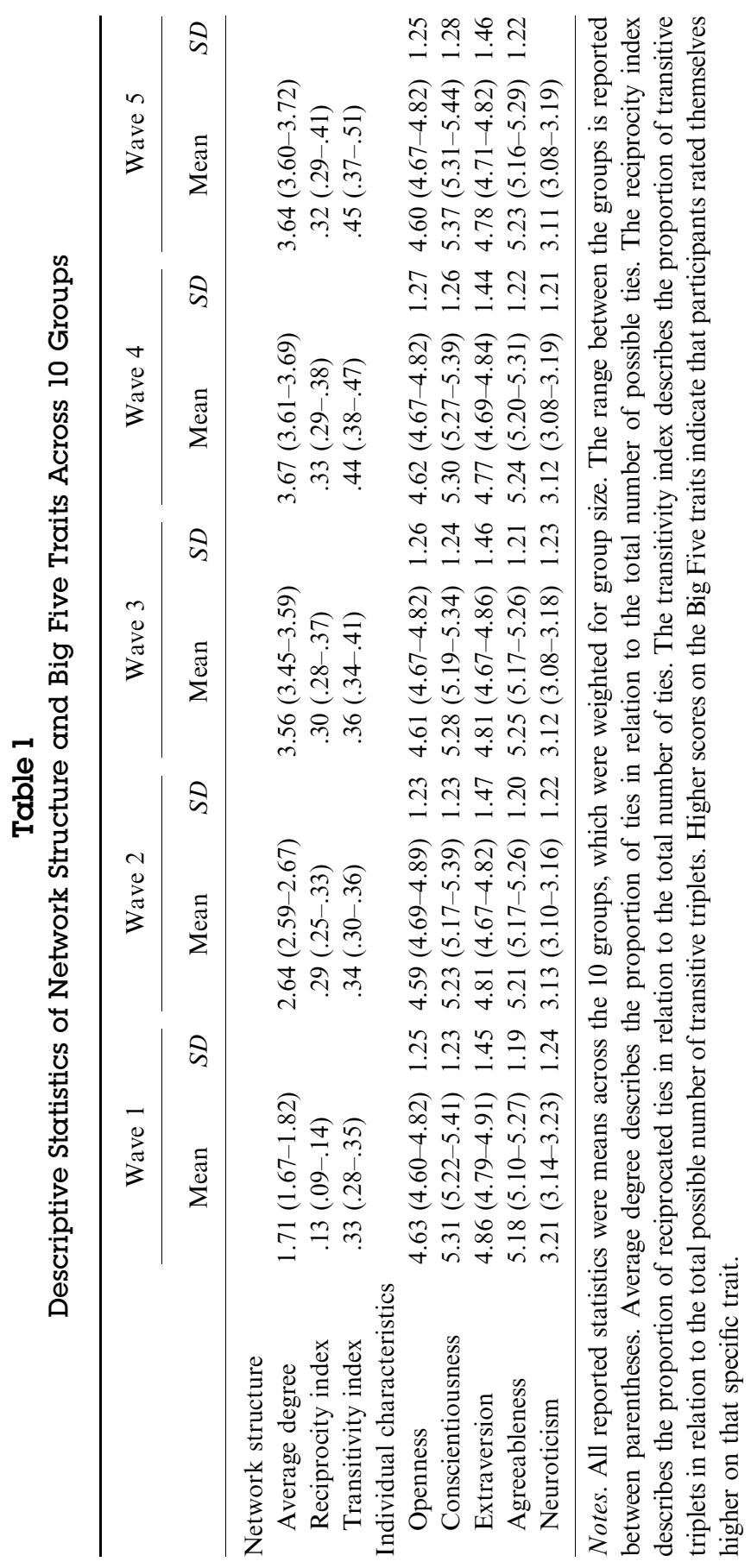


network and show increases in reciprocated and triadic friendship ties from the initial wave (in which very few individuals knew each other) over the first 3 months, followed by relative stability for most of these network characteristics.

The lower part of Table 1 presents means and standard deviations of all Big Five factors across the five waves weighted by participants' group size. Five repeated-measure analyses of variance (ANOVAs) showed no significant, $F(4,201)=.77-1.20, p>.10$, mean level changes in the Big Five traits across 4 months, suggesting that the average mean level of the Big Five traits remained stable across the course of the study.

\section{Specification of Final Network Model}

We initially tested a dyadic independence model to determine if adding transitivity and GD-2 each significantly increased the model fit. For transitivity, test statistics ranged from 15.68 to 23.43 $(\Delta d f=1)$ across the 10 groups, with $p<.001$. For GD-2, test statistics ranged from 84.68 to $93.43(\Delta d f=1)$ across the 10 groups, with $p<.001$. This indicates that adding the transitivity as well as the GD2 effect in the model significantly improves the fit of the model in all groups, warranting the use of a social network approach.

\section{Network Effects}

Table 2 presents aggregated estimates of four network effects: outdegree, reciprocity, transitivity, and geodesic distance-2. As expected, all emerged as significant predictors of friendship ties. The outdegree parameter was negative, indicating that individuals do not tend to nominate just anyone as a friend (friendship is a selective process). The reciprocity was positive, indicating that individuals tend to reciprocate friendship nominations over time. Finally, both indices pertaining to the formation of triadic friendships, namely, transitivity and geodesic distance-2, were significant. Specifically, the negative GD-2 measure indicated that, if individuals were indirectly befriended with a third person via one direct friend, they were more likely to select that third person directly over time. In addition, the positive transitivity effect indicated that the more friends individuals had that were befriended with a third person, the more they were likely to select the third person as direct friends. In sum, these two network effects suggest that individuals tended to form triadic 
Table 2

Multilevel Analysis of Ego, Alter, and Similarity Effects of Big Five Traits on Friendship Selection (10 Groups)

\begin{tabular}{|c|c|c|c|c|}
\hline \multirow[b]{2}{*}{ Parameter } & \multicolumn{2}{|c|}{ Mean Parameter } & \multicolumn{2}{|c|}{ Variance Parameter } \\
\hline & Estimate & $S E$ & Estimate & $\chi^{2}$ \\
\hline \multicolumn{5}{|l|}{ Network effects } \\
\hline Outdegree & $1.86^{* * * *}$ & .08 & .17 & 16.56 \\
\hline Reciprocity & $1.73^{* * * *}$ & .11 & .16 & 12.13 \\
\hline Geodesic distance-2 & $.52 * * * *$ & .06 & .04 & 14.46 \\
\hline Transitivity & $.14 * * * *$ & .02 & .00 & 6.04 \\
\hline \multicolumn{5}{|l|}{ Ego effects } \\
\hline Sex $(1=$ female $)$ & $.29 * *$ & .06 & .00 & 6.22 \\
\hline Openness & .02 & .15 & .10 & 14.97 \\
\hline Conscientiousness & .02 & .04 & .08 & 13.18 \\
\hline Extraversion & $.10 * * * *$ & .01 & .03 & 10.34 \\
\hline Agreeableness & .07 & .04 & .00 & 7.41 \\
\hline Neuroticism & .07 & .09 & .07 & 11.50 \\
\hline \multicolumn{5}{|l|}{ Alter effects } \\
\hline Sex $(1=$ female $)$ & .18 & .14 & .00 & 4.33 \\
\hline Openness & .01 & .05 & .10 & 15.14 \\
\hline Conscientiousness & .05 & .03 & .00 & 7.98 \\
\hline Extraversion & .01 & .03 & .00 & 5.30 \\
\hline Agreeableness & $.14 * * * *$ & .01 & .13 & 16.60 \\
\hline Neuroticism & .04 & .03 & .01 & 8.83 \\
\hline \multicolumn{5}{|l|}{ Similarity effects } \\
\hline Sex & $.40 * * * *$ & .12 & .00 & 8.52 \\
\hline Openness & $1.45^{* * * *}$ & .19 & $.31 * * *$ & 33.80 \\
\hline Conscientiousness & .17 & .19 & .26 & 11.53 \\
\hline Extraversion & $1.46^{* * * *}$ & .10 & $.35 * * * *$ & 33.29 \\
\hline Agreeableness & $1.55^{* * * *}$ & .03 & $.82 * *$ & 25.79 \\
\hline Neuroticism & .15 & .18 & .32 & 12.78 \\
\hline Conscientiousness & .17 & .19 & .26 & 11.53 \\
\hline
\end{tabular}

Note. Significance of the mean parameters is determined by dividing the parameter estimate by the standard error, adjusting for unreliable error variance across groups. Significance of the variance parameter is determined with a chi-square test with 9 degrees of freedom.

$* * p<.01, * * * p<.001$. 
friendships over time. This also means that data of the current study are consistent with the first assumption of SIENA analyses: Individuals tended to form friendships in a step-by-step manner by using existing ties in the peer network. To get some indication of the feasibility of the third assumption of SIENA analyses, that is, whether friendship ties tend to be stable rather than tend to change after being formed, the stability of friendship ties after being formed at the second measurement was examined (at the first measurement, they were just acquainted). Of all friendship ties being formed at Wave 2, $92 \%$ remained at Wave $3,88 \%$ at Wave 4 , and $82 \%$ at Wave 5. Thus, it seems that our data are consistent with the assumption that friendship ties tend to be enduring states rather than brief events.

\section{Effects of Sex}

Table 2 presents sex ego, sex alter, and sex similarity effects in the models. First, the sex ego effect was significant: Women tended to nominate more friends. Second, the sex similarity effect was significant, suggesting that men tended to select men and women tended to select women as friends.

\section{Effects of Personality Traits}

Table 2 presents the aggregated results of the parameters modeling various selection effects involving the Big Five personality characteristics.

To what extent do personality characteristics predict the number of selected friends? This question is addressed with the ego parameters for each of the personality measures. The only estimated parameter that emerged as a significant predictor of friendship ties was the Extraversion ego parameter. Individuals who rated themselves as high on Extraversion tended to nominate more friends. Thus, Extraversion predicts selecting more friends over time.

To what extent do personality characteristics predict being selected as a friend? This question is addressed with the alter parameters for each of the personality measures. The only estimated parameter that emerged as a significant predictor of friendship ties was the Agreeableness alter parameter. Individuals who rated themselves as more agreeable tended to receive more nominations. That is, individuals reporting higher levels of Agreeableness appeared to be more attractive (i.e., more popular) friendship partners. Thus, Agreeableness predicts being selected as a friend over time. 
To what extent do individuals select friends who have similar levels of personality characteristics? This question is addressed with the similarity parameters for each of the personality measures. Three of these effects emerged as positive and significant predictors of friendship ties: Agreeableness, Extraversion, and Openness. In other words, individuals tend to select friends with similar levels of Openness, Agreeableness, and Extraversion.

The last column of Table 2 shows whether the variance of the estimated parameter differs significantly from zero, that is, whether there are significant differences between the 10 groups in ego, alter, and similarity effects. The similarity in Openness, Agreeableness, and Extraversion estimates significantly differed across the 10 groups. Nevertheless, follow-up tests revealed the estimated similarity parameters were significant predictors of friendship ties in most of the groups ( 7 out of 10 groups for Openness, 10 out of 10 groups for Agreeableness, and 8 out of 10 groups for Extraversion), showing that, in most groups, individuals tended to select others with similar levels of Openness, Agreeableness, and Extraversion. All other parameter estimates were highly consistent in size across groups.

\section{DISCUSSION}

The current study is among the first to show the development of emerging friendship networks in late adolescence in a naturalistic setting. Results were consistent with suggestions concerning the increasing need of late adolescents to form new friendships because they enter a new phase of life (Neyer et al., 1999). On average, dyadic connections increased over time and seemed to stabilize after 3 months: Just-acquainted university students increasingly select others as friends and increasingly tend to reciprocate these friendship selections over the first 3 months. Moreover, the current study suggests that individuals increasingly form cohesive friendship networks, over and above the tendency to form dyadic relationships: The degree of transitivity increased in late adolescent friendship networks over time. That is, individuals tended to become friends with their friends' friends more and more. These results are consistent with a study showing that a small group of unacquainted university freshmen increasingly form reciprocated and transitive ties across the academic year (Van de Bunt et al., 1999). Moreover, all indica- 
tors of network expansion seem to stabilize after 3 months. However, because no information was used concerning the network after 4 months, future research should examine the subsequent development of emerging friendship networks.

Further, the current study examined to what extent justacquainted individuals select friends, are being selected as a friend, and select similar friends based on Big Five personality traits. Results indicated that three personality traits were uniquely associated with friendship selection: Extraversion, Agreeableness, and Openness. Extraversion appeared to be the most important factor in selecting friends. This is consistent with a study using a dyadic analysis, which suggested that Extraversion is the only personality trait that increases selecting friends over time (Asendorpf \& Wilpers, 1998). Prior studies have suggested that extraverted individuals experience more positive affect in social situations, making extraverted individuals more motivated to be socially active when getting acquainted (Ashton, Lee, \& Paunonen, 2002; Elphick et al., 1998). Thus, Extraverted individuals seem to select friends more, possibly because of increased positive affect in new social situations.

Second, actual similarity in Extraversion, or similarity according to individuals' self-ratings and their friends' self-ratings on Extraversion, predicted friendship selection over time: Extraverts tend to nominate each other as friends, and introverts tend to nominate each other as friends. Prior studies have found that mutual adolescent friends tend to show actual similarity in Extraversion (Selfhout et al., 2007), and several studies have shown that actual similarity in Extraversion predicts more relationship satisfaction in intimate relationships (e.g., Barelds \& Barelds-Dijkstra, 2007). Extraverts seem to interact in similar ways when getting acquainted: They are more talkative, less shy, and more spontaneous when first talking to strangers (Paulhus \& Trapnell, 1998). In contrast, introverts may be more cautious when first talking to others and interact in more shy, withdrawn ways. Similarity in ways of interacting may make interaction more predictable and enjoyable, which has been suggested to increase attraction between individuals, leading to more friendship selection (Berger \& Calabrese, 1975; Byrne \& Nelson, 1965). In sum, Extraversion seems to enhance selecting friends, and actual similarity in Extraversion seems to enhance selecting each other as friend.

Nevertheless, results of the current study suggested that Extraversion did not predict being selected as a friend over time. This contrasts with findings showing that Extraversion predicts peer 
popularity longitudinally (Lubbers et al., 2006; Paulhus \& Trapnell, 1998). An explanation for the difference between findings of prior studies compared to those in the current study is that we examined the unique effect of Extraversion on selection friends versus the unique effect of Extraversion on being selected as a friend. It could be that possible effects of Extraversion on being selected as a friend are confounded by effects of Extraversion on selecting friends: Individuals who tend to select more have a higher chance of being selected more as a friend as well (Steglich, Snijders, \& West, 2006). Therefore, it seems important to take personality effects on both processes simultaneously into account.

In contrast to Extraversion, Agreeableness predicted being selected more as a friend. This result is in line with prior studies showing that agreeable individuals are more popular with peers (Jensen-Campbell et al., 2007; Scholte et al., 1997). Agreeable individuals have a high desire to maintain positive relations with others and are characterized by tendencies toward cooperation, empathy, likeability, and friendly compliance (Rothbart, 1989). Therefore, peers may prefer agreeable individuals as friends.

Further, actual similarity in Agreeableness predicted friendship selection. This is consistent with the finding that mutual adolescent friends tend to be similar in Agreeableness (Selfhout et al., 2007). This result can be explained by a evolutionary approach to game theory (Gilchrist, 2007; Maynard Smith, 1984), which suggests that the more successful collaboration strategies for individuals are those based on a match between altruistic behaviors. Two individuals who act altruistically while interacting with each other gain most, followed by those who both act egoistically. The least profitable strategy is when there is a mismatch in altruistic behavior, because one invests only for the gains of the other. Hence, friends who are similar on Agreeableness may benefit more than those who are dissimilar, which could explain why similarity in Agreeableness enhances friendship selection. In sum, Agreeableness seems to enhance the probability of being selected as a friend, and similarity in Agreeableness seems to enhance selecting each other as a friend.

The finding that Agreeableness does not predict selecting friends does not support the conceptualization of Agreeableness as a higher enjoyment of others' company (Hogan, 1996) and confirms views emphasizing that Agreeableness pertains to altruistic behaviors more (Buss, 1991; Denissen \& Penke, 2008a). That is, Agreeableness, in 
contrast to Extraversion, does not seem to be associated with higher social activity. Instead, agreeable individuals may attract individuals more than extraverts because of their altruistic behaviors.

Unexpectedly, actual similarity in Openness also predicted friendship selection over time. Openness has traditionally been viewed as an intrapsychic trait, pertaining to individual differences in the structure and functioning of the mind, and therefore of little importance to social relationships (McCrae, 1996; McCrae \& Costa, 1994). However, although Openness in itself may be of small importance in selecting friends and being selected by friends, actual similarity in Openness might be associated with similarity in vocational choices (Holland, Johnston, Hughey, \& Asama, 1991), interests (McCrae, 1996), and values (Cheng, Bond, \& Chan, 1995). Actual similarity in values and interests specifically are thought to enhance interaction between individuals during acquaintanceship (Byrne \& Nelson, 1965; Clore \& Byrne, 1974). Consistent with the idea that similarity in Openness is considered desirable in friendship, one study showed that adolescents' self-rated Openness and their ratings on ideal friends' Openness were highly associated, even though Openness in itself was neither desirable nor undesirable as a personality trait (Cheng et al., 1995). In sum, although Openness may not predict selecting friends or being selected as a friend, a certain match in Openness may enhance friendship selection.

Further, women tended to nominate more partners, a result consistent with a prior study examining existing adolescent friendship networks (Burk et al., 2007). Regarding similarity, men tended to select men, and women tended to select women as friends. Because findings in this study as well as several prior studies (Burk et al., 2007; Kupersmidt, DeRosier, \& Patterson, 1995; Tolson \& Urberg, 1993; Urberg, Degirmencioglu, \& Tolson, 1998) indicate that this sex similarity effect on friendship selection is quite sizable, it is important to take into account the tendency for individuals to select friends of the same sex. Accordingly, all the discussed results were adjusted for sex differences on friendship selection processes.

Moreover, all discussed findings were adjusted for the tendency of individuals to form triadic friendships over time. More specifically, if individuals selected a friend, and this friend selected a third person as his or her friend, then individuals tended to select this third person as a friend over time as well (i.e., geodesic distance-2 effect). Additionally, this tendency to form triadic friendships 
increased if they had more friends connected to this third person (i.e., transitivity effect). In short, individuals tended to use the structure of the friendship network as a whole to select friends. As these network effects may be correlated with main effects and similarity effects of personality on friendship selection, they need to be taken into account when examining personality effects on friendship selection.

Overall, results suggested that effects of similarity in Big Five personality traits on friendship selection were greater than direct effects of personality traits on friendship selection. This suggests that a certain match in actual personality traits is especially important during friendship selection, even more so than individuals' absolute level of personality traits. This result contrasts findings based on the same data set suggesting that actual overall similarity in the Big Five traits does not predict friendship intensity among unacquainted freshmen over time (Selfhout et al., 2009). Nevertheless, the current study suggests that domain-specific similarity in Big Five personality, namely, similarity in Extraversion, Agreeableness, and Openness, does enhance friendship selection. This suggests the potential importance to examine specific, rather than overall, similarity in Big Five personality traits between individuals.

As expected, the current study did not find evidence for effects of Neuroticism and Conscientiousness on friendship selection during acquaintanceship. It might be that Neuroticism and Conscientiousness are associated more with maintaining relationships than with forming them. With regards to the former, self-esteem decreases more for neurotic individuals when they have conflicts with their romantic partner than for nonneurotic individuals, suggesting that neurotic individuals are more sensitive to social cues in existing relationships than nonneurotic individuals (Denissen \& Penke, 2008b). Conscientiousness seems to be an indicator of self-control processes, such as effortful control (Kochanska, Tjebkes, Forman, \& Kochenderfer-Ladd, 1998). Individuals who have poorer self-control seem to disclose personal information inappropriately, are more likely to engage in prejudiced behavior, are less responsive to their partners in romantic relationships, have poorer interpersonal interactions, and have impairment in everyday activities (Barkley, 1998; Finkel \& Campbell, 2001; Monteith, 1993). These behaviors seem to pertain to maintaining existing relationships more than to forming them. Thus, although these two factors do not seem to be associated with 
friendship selection during acquaintanceship, other research suggests that they may be important for existing relationships.

\section{Limitations}

One limitation of the current study is the reliance on a relatively highly educated sample, consisting primarily of female students. This may limit the choices individual had when choosing friends: to a certain degree, individuals were "forced" to select friends of the same gender and the same educational background. On the other hand, even when individuals have ample opportunities to interact with other-sex friends, they still tend to form same-sex friendships (Maccoby, 1988). Further, because social homogamy (i.e., individuals tend to form friendship with others that are similar to them in social background) is a pervasive fact of life, the high similarity in social background in the current study may form a realistic setting in which individuals usually form friendships. Further, we adjusted for sex effects as well as effects of sex composition of the dyad on friendship selection and still found effects of personality on friendship selection. Nevertheless, future studies should include individuals from various demographic backgrounds to investigate whether personality effects on friendship selection prevail after adjusting for the possible effect of social homogamy on friendship selection.

Additionally, the current study selected certain introduction groups on the basis of the number of participants that were willing to participate, which may have led to the selection of groups characterized by specific personality traits. Because personality data were not available for nonparticipants, we cannot adjust for potential differences between groups that participated and groups that did not participate. Nevertheless, all university freshmen were randomly assigned into the introduction groups, suggesting that it is less likely that individuals in certain groups would have higher scores on certain traits than others. Moreover, although we found that Conscientiousness indeed predicted attrition in the current study, this trait did not affect friendship selection.

Further, because the number of groups $(n=10)$ can be considered small for making reliable inference about between-group differences in effects, the between-group variance found in the results may be rather imprecise estimates. However, it should be noted that between-group differences were not the main focus of this study; 
rather, we investigated processes within groups while adjusting for between-group differences. Finally, SIENA models are currently limited to dichotomous network ties, so network data that consist of valued ties (e.g., a continuous measure of strength of relationship) had to be dichotomized for use in these models. Although the choice of an arbitrary cutoff value for dichotomization may affect results in general, additional analyses showed that choosing another cutoff value (contrasting best friends and good friends to other types of relationships) produced a similar pattern of results.

\section{Conclusion}

The social network approach offers several advantages over traditional statistical approaches. First, by using a social network approach, the development of emerging friendship networks was studied. This approach allowed us to show that, over and above the formation of reciprocated friendships, late adolescents tend to increasingly form triadic friendships. Moreover, the current study showed that accounting for the formation of cohesive network structures (i.e., the tendency of individuals to become friends with friends' friends) improved fit of the models of personality effects on friendship selection, suggesting that accounting for the network as a whole provides a more realistic model of friendship selection processes than using dyadic processes only. Taken together, results suggest that several Big Five factors play an important but differentiated role in initial friendship selection processes. Extraversion seems to increase selecting friends, whereas Agreeableness seems to increase being selected as a friend. Moreover, actual similarity in these personality traits as well as similarity in Openness seems to play an even more important role in enhancing friendship selection over time.

\section{REFERENCES}

Arnett, J. J. (2000). Emerging adulthood: A theory of development from the late teens through the twenties. American Psychologist, 55, 469-480.

Asendorpf, J. B., \& Denissen, J. J. A. (2006). Predictive validity of personality types versus personality dimensions from early childhood to adulthood: Implications for the distinction between core and surface traits. Merrill Palmer Quarterly, 52, 486-513.

Asendorpf, J. B., \& Wilpers, S. (1998). Personality effects on social relationships. Journal of Personality and Social Psychology, 74, 1531-1544. 
Ashton, M. C., Lee, K., \& Paunonen, S. V. (2002). What is the central feature of extraversion? Social attention versus reward sensitivity. Journal of Personality and Social Psychology, 83, 245-251.

Barelds, D. P. H., \& Barelds-Dijkstra, P. (2007). Love at first sight or friends first? Ties among partner personality trait similarity, relationship onset, relationship quality, and love. Journal of Social and Personal Relationships, 24, 479-496.

Barkley, R. A. (1998). Attention-deficit hyperactivity disorder: A handbook for diagnosis and treatment. New York: Guilford.

Berger, C. R., \& Calabrese, R. J. (1975). Some explorations in initial interaction and beyond: Toward a developmental theory of interpersonal communication. Human Communication Research, 1, 99-112.

Branje, S. J. T., Lieshout, C., \& Van Aken, M. A. G. (2004). Relations between Big Five personality characteristics and perceived support in adolescents' families. Journal of Personality and Social Psychology, 86, 615-628.

Brendgen, M., Vitaro, F., \& Bukowski, W. M. (2000). Stability and variability of adolescents' affiliation with delinquent friends: Predictors and consequences. Social Development, 9, 205-225.

Bukowski, W. M., \& Newcomb, A. F. (1984). Stability and determinants of sociometric status and friendship choice: A longitudinal perspective. Developmental Psychology, 20, 941-952.

Burk, W., Steglich, C. E. G., \& Snijders, T. A. B. (2007). Beyond dyadic interdependence: Actor-oriented models for co-evolving social networks and individual behaviors. International Journal of Behavioral Development, 31, 397-404.

Buss, D. M. (1991). Evolutionary personality psychology. Annual Review of Psychology, 42, 459-491.

Byrne, D. (1971). The attraction paradigm. New York: Academic Press.

Byrne, D., \& Nelson, D. (1965). Attraction as a linear function of proportion of positive reinforcements. Journal of Personality and Social Psychology, 1, 659663.

Carrington, P., Scott, J., \& Wasserman, S. (2005). Models and methods in social network analysis. New York: Cambridge University Press.

Cheng, C., Bond, M. H., \& Chan, S. C. (1995). The perception of ideal best friends by Chinese adolescents. International Journal of Psychology, 30, 91-108.

Clore, G. L., \& Byrne, D. A. (1974). A reinforcement-affect model of attraction. In T. L. Huston (Ed.), Foundations of interpersonal attraction (pp. 143-165). New York: Academic Press.

Cochran, W. G. (1954). The combination of estimates from different experiments. Biometrics, 10, 101-129.

Denissen, J. J. A., Geenen, R., Selfhout, M. H. W., \& Van Aken, M. A. G. (2008). Single-item Big Five ratings in a social network design. European Journal of Personality, 22, 37-54.

Denissen, J. J. A., Geenen, R., Van Aken, M. A. G., Gosling, S. D., \& Potter, J. (2008). Development and validation of a Dutch translation of the Big Five inventory (BFI). Journal of Personality Assessment, 90, 152-157.

Denissen, J. J. A., \& Penke, L. (2008a). Individual reaction norms underlying the Five Factor Model of personality: First steps towards a theory-based conceptual framework. Journal of Research in Personality, 42, 1285-1302. 
Denissen, J. J. A., \& Penke, L. (2008b). Sociometer sensitivity: Associations between Neuroticism and reactions to cues of social inclusion. European Journal of Personality, 22, 497-517.

Digman, J. M. (1990). Personality structure: Emergence of the five-factor model. Annual Review of Psychology, 41, 417-440.

Elphick, E., Halverson, C. F., \& Marszal-Wisniewska, M. (1998). Extraversion: Toward a unifying description from infancy to adulthood. In I. Mervielde, V. L. Havill, G. A. Kohnstamm, \& C. F. J. Halverson (Eds.), Parental descriptions of child personality: Developmental antecedents of the Big Five? (pp. 21-48). Mahwah, NJ: Erlbaum.

Finkel, E. J., \& Campbell, W. K. (2001). Self-control and accommodation in close relationships: An interdependence analysis. Journal of Personality and Social Psychology, 81, 263-277.

Fleeson, W., Malanos, A. B., \& Achille, N. M. (2002). An intraindividual process approach to the relationship between extraversion and positive affect: Is acting extraverted as "good" as being extraverted? Journal of Personality and SocialPsychology, 83, 1409-1422.

Freedman, J. L., \& Doob, A. N. (1968). Deviancy: The psychology of being different. Oxford, UK: Academic Press.

Gilchrist, J. S. (2007). Cooperative behaviour in cooperative breeders: Costs, benefits, and communal breeding. Behavioural Processes, 76, 100-105.

Gosling, S. D., Rentfrow, P. J., \& Swann, W. B. (2003). A very brief measure of the Big-Five personality domains. Journal of Research in Personality, 37, 504-528.

Hamm, J. (2000). Do birds of a feather flock together? The variable bases for African, Asian American, and European American adolescents' selection of similar friends. Developmental Psychology, 36, 209-219.

Hedges, L. V., \& Olkin, I. (1985). Statistical methods for meta-analysis. Orlando, FL: Academic Press.

Hogan, R. T. (1996). A socioanalytic perspective on the five-factor model. In J. S. Wiggins (Ed.), The five factor model of personality: Theoretical perspectives (pp. 163-179). New York: Guilford Press.

Holland, J., Johnston, J., Hughey, K., \& Asama, N. (1991). Some explorations of a theory of careers: VII. A replication and some extentions. Journal of Career Development, 81, 91-100.

Holmes, J. G. (2002). Interpersonal expectations as the building blocks of social cognition: An interdependence theory perspective. Personal Relationships, 9 , $1-26$.

Huisman, M., \& Snijders, T. A. B. (2003). Statistical analysis of longitudinal network data with changing composition. Sociological Methods and Research, 32, 253-287.

Jensen-Campbell, L. A., Gleason, K. A., Adams, R., \& Malcolm, K. T. (2003). Interpersonal conflict, agreeableness, and personality development. Journal of Personality, 71, 1059-1085.

Jensen-Campbell, L. A., Knack, J. M., Waldrip, A. M., \& Campbell, S. D. (2007). Do Big Five personality traits associated with self-control influence the regulation of anger and aggression? Journal of Research in Personality, 41, 403-424. 
Katz, L., \& Proctor, C. H. (1959). The configuration of interpersonal relations in a group as a time-dependent stochastic process. Psychometrika, 24, 317-327.

Knecht, A. (2008). Friendship selection and friends' influence. Dynamics of networks and actor attributes in early adolescence. Doctoral dissertation, University of Utrecht.

Kochanska, G., Tjebkes, T. L., Forman, D. R., \& Kochenderfer-Ladd, B. J. (1998). Children's emerging regulation of conduct: Restraint, compliance, and internalization from infancy to the second year. Child Development, 69, 1378-1389.

Kupersmidt, J. B., DeRosier, M. E., \& Patterson, C. P. (1995). Similarity as the basis for children's friendships: The roles of sociometric status, aggressive and withdrawn behavior, academic achievement and demographic characteristics. Journal of Social and Personal Relationships, 12, 439-452.

Lubbers, M. J., Van Der Werf, M. P. C., Kuyper, H., \& Offringa, G. J. (2006). Predicting peer acceptance in Dutch youth: A multilevel analysis. Journal of Early Adolescence, 26, 4-35.

Luo, S., \& Klohnen, E. C. (2005). Assortative mating and marital quality in newlyweds: A couple-centered approach. Journal of Personality and Social Psychology, 88, 304-326.

Lusk, J., MacDonald, K., \& Newman, J. R. (1998). Resource appraisals among self, friend and leader: Implications for an evolutionary perspective on individual differences. Personality and Individual Differences, 24, 685-700.

Maccoby, E. E. (1988). Gender as a social category. Developmental Psychology, 24, 755-765.

Maynard Smith, J. (1984). Game theory and the evolution of behaviour. Behavioral and Brain Sciences, 7, 95-125.

McCrae, R. R. (1996). Social consequences of experiental openness. Psychological Bulletin, 120, 323-337.

McCrae, R. R., \& Costa, P. T. (1994). The stability of personality: Observation and evaluations. Current Directions in Psychological Science, 3, 173-175.

McPherson, M., Smith-Lovin, L., \& Cook, J. (2001). Birds of a feather: Homophily in social networks. Annual Review of Sociology, 27, 415-444.

Monteith, M. J. (1993). Self-regulation of prejudiced responses: Implications for progress in prejudice-reduction efforts. Journal of Personality and Social Psychology, 65, 469-485.

Murphy, L. M. (2005, April). Friends are not more similar than nonfriends, but they think that they are. Paper presented at the Society for Research on Child Development, Atlanta.

Nettle, D. (2006). The evolution of personality variation in humans and other animals. American Psychologist, 61, 622-631.

Neyer, F. J., Banse, R., \& Asendorpf, J. B. (1999). The role of projection and empathic accuracy in dyadic perception between older twins. Journal of Social and Personal Relationships, 16, 419-442.

Paulhus, D. L., \& Trapnell, P. D. (1998). Typological measures of shyness: Additive, interactive, and categorical. Journal of Research in Personality, 32, 183-201. 
Roberts, B. W., \& Mroczek, D. (2008). Personality trait change in adulthood. Current Directions in Psychological Science, 17, 31-35.

Rothbart, M. K. (1989). Biological processes in temperament. In G. Kohnstamm, J. Bates, \& M. K. Rothbart (Eds.), Temperament in childhood (pp. 77-110). Chichester, UK: Wiley.

Scholte, R. H. J., Van Aken, M. A. G., \& Van Lieshout, C. F. M. (1997). Adolescent personality factors in self-ratings and peer nominations and their prediction of peer acceptance and peer rejection. Journal of Personality Assessment, 69, 534-554.

Schweinberger, M. (2005). Statistical modeling of network panel data: goodnessof-fit. Manuscript in preparation.

Selfhout, M., Branje, S., Raaijmakers, Q., \& Meeus, W. (2007). Similarity in adolescent best friendships: The role of gender. The Netherlands Journal of Psychology, 63, 50-57.

Selfhout, M., Denissen, J. J. A., Branje, S., \& Meeus, W. (2009). In the eye of the beholder: Perceived, actual, and peer-rated similarity in personality, communication, and friendship intensity during the acquaintanceship process. Journal of Personality and Social Psychology, 96, 1152-1165.

Snijders, T. A. B. (2001). The statistical evaluation of social network dynamics. Sociological Methodology, 31, 361-395.

Snijders, T. A. B. (2009). Longitudinal methods of network analysis. In B. Meyers (Ed.), Encyclopedia of complexity and system science. New York: Springer Verlag.

Snijders, T. A. B., \& Baerveldt, C. (2003). A multilevel network study of the effects of delinquent behavior on friendship evolution. Journal of Mathematical Sociology, 27, 123-151.

Snijders, T. A. B., Steglich, C. E. G., \& Schweinberger, M. (2007). Modeling the co-evolution of networks and behavior. In K. Van Montfort, H. Oud, \& A. Satorra (Eds.), Longitudinal models in the behavioral and related sciences (pp. 41-71). Mahwah, NJ, Erlbaum.

Snijders, T. A. B., Steglich, C. E. G., Schweinberger, M., \& Huisman, M. (2006). Manual for SIENA (Vol. 3). Groningen: University of Groningen.

Snijders, T. A. B., Steglich, C. E. G., \& Van de Bunt, G. G. (in press). Introduction to stochastic actor-based models for network dynamics. Social Networks.

Sprecher, S., \& Regan, P. C. (2002). Liking some things (in some people) more than others: Partner preferences in romantic relationships and friendships. Journal of Social and Personal Relationships, 19, 463-481.

Steglich, C. E. G., Snijders, T. A. B., \& West, P. (2006). Applying SIENA: An illustrative analysis of the coevolution of adolescents' friendship networks, taste in music, and alcohol consumption. Methodology: European Journal of Research Methods for the Behavioral and Social Sciences, 2, $48-56$.

Sunnafrank, M., \& Ramirez, A., Jr. (2004). At first sight: Persistent relational effects of get-acquainted conversations. Journal of Social and Personal Relationships, 21, 361-379.

Tolson, J. M., \& Urberg, K. A. (1993). Similarity between adolescent best friends. Journal of Adolescent Research, 8, 274-288. 
Urberg, K. A., Degirmencioglu, S. M., \& Tolson, J. M. (1998). Adolescent friendship selection and termination: The role of similarity. Journal of Social and Personal Relationships, 15, 703-710.

Van de Bunt, G. G., Van Duijn, M. A. G., \& Snijders, T. A. B. (1999). Friendship networks through time: An actor-oriented statistical network model. Computational and Mathematical Organization Theory, 5, 167-192.

Wasserman, S., \& Faust, K. (1994). Social network analyses. Methods and applications. Cambridge: Cambridge University Press.

Wasserman, S., \& Pattison, P. E. (1996). Logit models and logistic regression for social networks: I. An introduction to Markov graphs and p*. Psychometrika, 61, 401-425. 